\title{
$\mathrm{SBCD}(\mathrm{School}$ Based Curriculum Development)의 개념변화에 따른 개발요인 설정에 관한 연구
}

\author{
이재철 ${ }^{1}$, 최화숙 ${ }^{*}$ \\ ${ }^{1}$ 여주여자중학교, ${ }^{2}$ 서남대학교 교직과
}

\section{The Study on Development Factor Establishing According to SBCD's Conceptual Change}

\author{
Jae-Cheol Lee ${ }^{1}$ and Hwa-Suk Choi ${ }^{*}$ \\ ${ }^{1}$ Yeoju Girl's Middle School, ${ }^{2}$ Dept. of Education, Seonam University
}

\begin{abstract}
요 약 본 연구는 학교중심교육과정개발(School Based Curriculum Development 이하 SBCD)의 개념변화에 따라 개발상에 고려되어야 할 요인들이 무엇인지에 대해 알아보고자 문헌분석과 전문가협의회를 통해 고찰하였다. 전 세계적인 추세와 국 내외의 연구동향을 중심으로 현재 $\mathrm{SBCD}$ 가 안고 있는 문제점들을 진단하고 비중있게 고려되어야 할 개발요인들을 폭넓게 조망하였다. 연구의 결과 첫째, $\mathrm{SBCD}$ 는 국가수준 교육과정의 수용정도에 따라 폭넓게 구분될 수 있다. 둘째, $\mathrm{SBCD}$ 에 대한 국가와 단위학교의 이해가 상이했다. 셋째, 개발요인은 3 가지 영역(인적·내용·환경영역)의 9 가지 요인(직·간접·기타 참여요 인, 정규·방과후·특별 교육과정, 지원체계, 교육환경, 분위기)으로 세분화할 수 있다. 효과적인 $\mathrm{SBCD}$ 를 시도하려는 이해당사 자들을 위해 $\mathrm{SBCD}$ 의 개념변화에 따른 개발요인들을 다각적으로 고찰한 본 논문은 향후 지속적인 $\mathrm{SBCD}$ 의 갱신과 실증연구 를 위한 토대를 제공할 수 있을 것으로 기대한다.
\end{abstract}

\begin{abstract}
The purpose of this study was to discuss the factors according to SBCD conceptual change by literature analysis and FGI(focus group interview). It's to identify the problem of SBCD centered around world-wide and research trends. Also this study briefly surveys the current factors considered in SBCD.

The results were as follows First, SBCD is able to be classified according to national curriculum level's acceptance degree. Second, each nation and school had a different understanding to the SBCD. Third, this study developed three domains(human, content, and environment) and nine factors(principals, teachers, students, parents, community people, regular curriculum, after school curriculum, other special programs, and school environment) based on literature analysis and FGI to develop SBCD. As observed by the above results, it will provide schools with the groundwork for discussion of increasing chances for successful curriculum development with continuous extending of SBCD.
\end{abstract}

Key Words : SBCD(School Based Curriculum Development), Curriculum Development

\section{1. 서론}

학교교육과정에는 해당 학교의 교육목표와 교육 중점, 경영철학, 전통, 대·내외적 특성 등을 고려하여 학교만의 창의적이고 독특한 교육내용 및 운영방식 등이 반영되어 야 하므로 모든 학교가 제각기 다양한 모습을 보일 수 있
다. 또한, 국가에서 제시하는 교육과정이 아무리 이상적 이라 할지라도 그것을 단위학교에 곧바로 적용하는 것은 일정한 한계가 생길 수 있다[1]. 다시 말해, 학교교육과정 은 교육목표와 내용만을 의미하는 기존의 단순한 개념에 서 벗어나, 학습자의 총체적 교육경험을 관리하는 실천 적이고, 포괄적인 개념으로 인식되어야 한다. 따라서 단

\footnotetext{
*Corresponding Author : Hwa-Suk Choi(Seonam Univ.)

Tel: +82-10-9186-2637 email: hwa0680@naver.com

Received December 19, 2013

Revised (1st January 13, 2014, 2nd January 16, 2014)

Accepted April 10, 2014
} 
위학교가 자체적으로 당면한 현실을 극복하고, 학생들의 특성 및 지역사회의 실정에 맞추어 교육과정을 만들고 운영해야 함은 당연하고도 시급한 과제라 할 수 있다.

$\mathrm{SBCD}$ 에 대한 연구는 1960년대 호주를 중심으로 시작 하여 여러 나라에 전파되었고, 1980년대에 접어들면서 본격적인 연구가 진행되었다[2]. 우리나라에서도 제6차 교육과정에서부터 단위학교에 $\mathrm{SBCD}$ 의 편성·운영권을 부분적으로 부여했고, 제7차, 2007·2009 개정 교육과정에 이르기까지 교육과정 자율화 정책의 일환으로 그 중요성 을 확대시켜 왔다.

현재 우리나라는 $\mathrm{SBCD}$ 에 대한 법적 근거를 교육부와 시·도교육청의 고시 및 지침으로 규정하고 있으며, 이를 근거로 단위학교에서는 필요한 역할을 수행해야 한다고 명시하고 있다. 그러나 고시와 지침은 일정한 선언적 의 미만을 가질 뿐, $\mathrm{SBCD}$ 의 개념변화를 적시에 수용하지 못하고 있으며, 개발요인들이 무엇이고, 이에 대한 구체 적인 역할과 내용이 어떠해야 하는 지에 대한 언급이 모 호하여 많은 논란을 야기하고 있다[3]. 현재 $\mathrm{SBCD}$ 의 개 념은 세계적인 흐름으로 각 단위학교가 처해진 교육상황 을 적극적으로 해결하는 '창안'의 개념으로 확대되고 있 음에도 불구하고, 우리나라의 교육현장에서는 국가의 고 시와 지침을 그대로 받아들이는 '수용'의 형태에 고착되 어 있어 시급한 인식개선이 필요하다.

그 동안 교육과정이 개정될 때마다, 교육부나 시·도교 육청 단위로 새로운 교육과정의 이해를 돕기 위한 형식 적인 연수들이 상명하달(上命下達)식으로 이루어져 왔다 [3]. 또한 현직 교원을 대상으로 실시하는 $\mathrm{SBCD}$ 관련 직 무연수의 경우도, 예비교사 과정에서나 필요한 지극히 일반적이고 지엽적인 내용들로 구성되어 효과적인 $\mathrm{SBCD}$ 를 위한 해결의 실마리를 제시하는데 매우 미흡했 다. 이러한 연유로 학교 현장에서는 $\mathrm{SBCD}$ 를 구성원 모 두의 임무가 아닌, 일부의 전문가 및 담당자에게 맡겨진 일이라는 의식이 팽배하게 되었다[4]. 바람직한 $\mathrm{SBCD}$ 를 위해서는 특정한 소수가 아닌 폭넓은 인력들이 다양한 영역에 걸쳐 심도있게 참여해야 함이 마땅하다. 이에 $\mathrm{SBCD}$ 에 비중있게 고려되어야 할 요인들을 구체적으로 파악하려는 노력이 일차적으로 필요하다.

이러한 부분들에 주목하여 본 연구는 구체적으로 다 음과 같은 두 가지의 연구목적을 설정하였다.

첫째, 성공적인 $\mathrm{SBCD}$ 를 시도하려는 이해당사자들에 게 올바른 이해의 바탕을 마련한다는 측면에서 $\mathrm{SBCD}$ 의
개념변화를 제시하고자 한다.

둘째, 단위학교의 효과적인 $\mathrm{SBCD}$ 를 위한 문제해결의 실마리를 제공한다는 측면에서 $\mathrm{SBCD}$ 에 고려해야 할 요 인들이 무엇인지를 제시하고자 한다.

\section{2. $\mathrm{SBCD}$ 의 개념변화}

$\mathrm{SBCD}$ 에 대한 초기의 논의로 Skilbeck(1884)은 의사 결정과정을 중시하는 입장에서 "학생들이 다니는 교육기 관에서 학습 프로그램을 계획·설계·실행·평가하는 것”으 로 정의[5]했고, Bezzina(1991)는 인적요인의 활동을 강 조하며 “구성원 전체가 학교에서 제공하는 교육과정의 모든 부분이나 특정 부분을 계획·실행·평가하는 과정”이 라고 정의[6]하였으며, $\operatorname{Sabar(1991)ㄴㅡㄴ~ㅈㅏㅇㅠㄹㅅㅓㅇㅇㅡㄹ~ㅈㅜㅇㅅㅣㅎㅏ~}$ 며, "단위학교가 교육과정의 계획·설계·평가와 관련된 모 든 결정을 외부의 강요나 압력 없이 내부역량을 바탕으 로 자율적으로 수립하는 것”으로 정의[7]하였다. 이러한 정의들은 공통적으로 $\mathrm{SBCD}$ 의 의사결정권과 통제권이 단위학교에 있어야 함을 강조하고 있다.

국내에서도 세계적인 흐름에 발맞춰 곽병선(1987)은 $\mathrm{SBCD}$ 를 “단위학교가 의사를 결정하고 통제하는 과정" 으로 정의[8]하였고, 김재춘(2000)은 “국가에서 고시한 기준과 시·도교육청의 지침을 근거로 지역의 특수성과 학교의 실정, 학생의 실태에 알맞게 마련한 당해 학교의 구체적인 실행”으로 정의[9]하였다. 또한, 권낙원(2008) 은 “국가수준 교육과정에 근거하고 지역의 특수성, 해당 학교의 여건, 학생 및 학부모의 필요와 요구 등에 적합한 교육목표, 내용, 방법, 평가에 관한 단위학교 계획”으로 정의[10]하였다. 이러한 국내의 정의들은 국가수준 교육 과정을 $\mathrm{SBCD}$ 의 근간으로 삼고 있다는 점에서 해외 학자 들의 정의와 상이하다.

$\mathrm{SBCD}$ 에 대한 국내외 학자들의 정의를 종합하여, 국 가수준 교육과정에 대한 수용정도를 준거로 정리를 해보 면 Table 1 과 같다. 수용정도는 있는 그대로의 전면적 수 용을 채택, 부분적 수용을 재구성, 미수용을 창안으로 구 분하였다. 
[Table 1] The SBCD summary according to acceptance degree about curriculum of national level

\begin{tabular}{|c|c|c|c|}
\hline \multirow{2}{*}{$\begin{array}{l}\text { scholar } \\
\text { name }\end{array}$} & \multicolumn{3}{|c|}{ acceptance degree } \\
\hline & adoption & restructure & invention \\
\hline Skillbeck(1984) & & & 0 \\
\hline Bezzina(1991) & & & O \\
\hline Sabar(1991) & & & O \\
\hline B. S. Gwak(1987) & & & 0 \\
\hline J. C. $\operatorname{Kim}(2000)$ & & 0 & \\
\hline N. W. Kweon(2008) & & 0 & \\
\hline
\end{tabular}

Table 1에서 볼 수 있듯이, 국내의 학자들은 국외의 학자들에 비해 상대적으로 높은 국가수준 교육과정의 수 용정도를 보였다. 이는 급속한 산업화와 더불어 효율적 인 인적자원 개발이 강조되며, 실효성만을 강조해왔던 정책적 상황들이 $\mathrm{SBCD}$ 에 반영된 결과로 볼 수 있다. 이 는 자율성을 바탕으로 단위학교의 $\mathrm{SBCD}$ 의 '재구성' 및 '창안'이 급속히 추진된 세계적인 흐름과 대조를 이루는 부분이다.

미국의 교육평가기준공동위원회(JCSEE: The Joint Committee on Standard for Educational Evaluation, 2011)에서는 $\mathrm{SBCD}$ 를 '정기적으로 학생들에게 제공하는 활동의 계획'으로 폭넓게 규정하고, 바람직한 $\mathrm{SBCD}$ 의 평가기준으로 유용성(utility), 실행가능성(feasibility), 적 합성(propriety), 정확성(accuracy), 책무성(accountability)의 5 가지를 제시[12]하고 있다. 특히 책무성(accountability) 은 당해 학생들을 위한 단위학교의 $\mathrm{SBCD}$ 창안에 대한 자구적인 노력을 강조하는 기준으로 제시되고 있다.

이상의 내용들을 감안할 때, 우리나라의 경우도 $\mathrm{SBCD}$ 의 개념이 국가수준 교육과정을 그대로 '수용'하거 나 부분적으로 '재구성'하는 수준에서 시급히 탈피해야 할 것이다. 다시 말해, $\mathrm{SBCD}$ 는 단위학교가 자율성을 바 탕으로 다양한 현실을 고려하여 비전과 목표를 향해 교 육과정을 '창안'하는 활동으로 그 개념이 인식되어야 한 다는 것이다. 제한된 개념정의에서 벗어나는 것은 현재 $\mathrm{SBCD}$ 와 관련해 폭넓게 영향력을 발휘하고 있는 다양한 자원들의 역동성을 논의함에도 타당한 근거가 될 수 있다.

\section{3. $\mathrm{SBCD}$ 의 요인 탐색}

\subsection{SBCD에 관한 연구패턴의 메타적 분석}

먼저 $\mathrm{SBCD}$ 를 핵심어로 1995년 이후부터 현재까지 국 회전자도서관에 등록된 총 56 편의 연구논문들을 수집하 였다. 연구들이 저마다 상이한 척도와 방법들로 이루어 져 있어, 양적연구의 유형들은 효과크기(effect size)를 고려하여 주로 .80 이상의 큰 효과크기를 보인 연구결과 들을 중심으로 분석했고, 면담과 사례연구 등 질적연구 의 유형들은 주된 유목들과 시사점을 중심으로 살펴보았 다. 그 결과, $\mathrm{SBCD}$ 에 관한 연구패턴은 크게 4 가지의 흐 름들로 나눌 수 있다.

첫 번째로, $\mathrm{SBCD}$ 의 의의를 다룬 패턴으로 주로 $\mathrm{SBCD}$ 에 대한 소개와 향후 과제 등을 논의하고 있었다 [12-15]. 공통적으로 $\mathrm{SBCD}$ 의 중요성과 시대적인 추세에 따라 단위학교의 역할증대를 일차적으로 강조하고 있었 다. 우리나라에서 특히 이러한 유형의 연구들이 비교적 오랜 기간 진행된 것은 아직까지 $\mathrm{SBCD}$ 가 미흡하게 이루 어지고 있음을 방증하는 것으로 보인다. 또한, 한목소리 로 이론 중심의 획일적인 개발방식에서 벗어나 다양한 인적자원들이 상호보완적인 역할을 수행해야 함을 향후 과제로 제시하고 있었다. 현재 $\mathrm{SBCD}$ 가 소수의 개발 집 단만을 중심으로 이루어져 다양한 의견을 수용하는데 제 한적이라는 지적은 깊이 고민해 볼 문제로 보인다.

두 번째는 $\mathrm{SBCD}$ 의 설계와 모형에 관한 연구패턴 [16-18]으로, 주로 문헌·조사연구를 통해 합리적인 절차 와 단계를 제시하려는 논의들로 볼 수 있다. 대부분이 교 육목표 설정이나 요구분석, 상황분석 혹은 강령 등의 용 어로 나름의 논리를 설명하고 있었는데, 공통적인 향후 과제로 $\mathrm{SBCD}$ 의 과정상에 수반되는 다양한 요인들을 밝 히고, 이들의 중요도를 고려해야 함을 향후 과제로 제시 하고 있었다.

세 번째는, $\mathrm{SBCD}$ 의 과정에 관한 맥락적인 연구패턴 [19-22]으로 대부분이 직업학교와 대안학교를 중심으로 이루어졌다. 개발의 방법과 실천에 관심을 갖고, 원론적 인 내용보다는 개발이 진행되는 실천적인 과정에 주목하 고 있었다. 이 흐름은 개별사례들의 효과에 주목하여 $\mathrm{SBCD}$ 의 맥락적 과정과 인적 요인들의 역할을 설명하고 있다는 점에서 시사하는 바가 컸고, 향후 $\mathrm{SBCD}$ 의 중요 연구분야로 확대되어 지속적인 논의가 있을 것으로 보인다.

끝으로, $\mathrm{SBCD}$ 의 다양한 요인도출에 관한 연구패턴 
[23-25]으로 대부분이 학교장과 교사의 역할에 주목하고 있었다. 또한, $\mathrm{SBCD}$ 요인을 학자들마다 개발·운영요인 혹은 물질·조건적 요인 등의 명칭으로 나누어 제시하고 있었다. 연구자마다 중복되는 요인들이 많았지만 전반적 인 흐름은 종래의 인적요인에만 치우친 연구에서 벗어나 학교를 둘러싼 다양하고 맥락적인 상황요인과 환경요인 에 관심을 둘 필요가 있다는 것이다.

\section{2 $\mathrm{SBCD}$ 의 구성요소 - 원리 - 준거에 관한 분석}

\subsubsection{SBCD의 구성요소}

$\mathrm{SBCD}$ 의 구성요소에 대해 Glatthorn(1994)은 철학과 비전, 교과목에 대한 기저, 지식, 중점사항, 지역의 교육 목표, 교과목표, 교과내용, 범위와 계열, 학년목표, 시간배 당, 학습목표의 계열, 각 목표에 대한 활동, 평가수단, 교 과서와 기타 교수자료, 교육과정의 다양화 등이 포함되 어야 한다고 밝히고 있다[26]. 또한, Marsh(1999)는 이론 이나 합당한 근거, 교육과정 영역의 범위, 일반적 목적과 교과목표, 교과의 설계지침, 내용, 교수-학습 원리, 교과 평가 등이 포함되어야 한다고 설명하였다[27]. 이러한 구 성요소들은 개별적 혹은 비슷한 역할을 수행하는 요소들 이 하나의 군으로 묵여, $\mathrm{SBCD}$ 에 영향을 주는 중요요인 으로 작용할 수 있다.

\subsection{2 $\mathrm{SBCD}$ 의 구성원리}

$\mathrm{SBCD}$ 의 구성원리로 대학교직과교재편찬위원회(2008) 에서는 최소필수요소, 지역성, 시대성, 사회와 개인의 융 화 및 계속발전성의 원리를 제시하고 있다[28]. 최소필수 요소의 원리란, 교육과정에 구성되는 내용은 어느 정도 의 깊이와 범위를 갖고 있으며, 이것은 어떤 지역이나 사 회에 통용되는 최소한의 공통성이 교과교육의 내용면에 포함되어야 한다는 것이다. 지역성의 원리란 지역사회의 특성과 사상들이 충분히 고려되어야 함을 나타낸다. 이 는 지역사회학교 운동의 전개에 따라 학교의 사회화가 강조되며, 최근 중요한 교육과정 구성원리로 등장하게 되었다. 시대성의 원리란, 교육과정 구성은 시대적 흐름 에 발맞춰 각 시대적 요구가 충실히 반영되도록 구성되 어야 한다는 원리이다. 사회와 개인의 융화 원리란, 교육 이란 본래 그 자체가 개인의 완성과 사회의 발전을 그 이 상으로 삼고 있는 것이기 때문에 교육과정의 구성에 있 어서도 당연히 이러한 두 측면의 조화가 이루어져야 한 다는 원리이다. 마지막으로 계속 발전성의 원리란, 학교
교육이 학습자의 성장을 돕고 그들의 보다 나은 인간형 성을 위해서 발전적인 방향에서 계속되어야 한다는 것 이다.

이상에서 제시된 교육과정 구성원리 가운데 특히 어 떤 지역에서나 사회에 통용되는 최소한의 공통성이 교육 내용면에 포함되어야 한다는 최소필수요소, 지역사회의 특성과 사상들을 충분히 고려해야 한다는 지역성, 시대 적 흐름에 발맞춰 그 요구가 충실히 반영되어야 한다는 시대성의 원리는 $\mathrm{SBCD}$ 의 요인 설정에 있어 꼼꼼히 되짚 어보아야 할 부분이다. 특히 지역성은 최근 학부모나 지 역사회인사들의 학교 참여가 늘어나고, 지역인프라를 학 교교육 전반에 적극 활용하려는 움직임과 밀접한 관련이 있으므로 인적요인의 다양성 및 교육환경 확대와 관련해 함께 논의될 필요가 있다.

\subsection{3 $\mathrm{SBCD}$ 의 준거}

교육과정 개발의 처방적 모형제시를 통해 많은 공헌 을 한 Tyler(1949)는 교육과정 개발준거로 교육목표를 설정하는 단계에서 학습자·사회·교과전문가의 요구를 준 거로 목표를 추출하고, 교육철학과 학습심리학이 이를 평가하기 위한 여과장치가 될 수 있다고 하였다[29]. 또 한, Schwab(1969)은 교육과정은 보다 현실적이며 구체 적인 장면에서 연구·개발될 필요가 있음을 주장하며 구 체적으로 학습자, 교사, 교재, 환경을 중심으로 탐구되어 야 한다는 견해를 밝히고 있다[30].

$\mathrm{SBCD}$ 의 준거에 관해 언급한 연구들[23,24,29,30]은 일 반적으로 다음과 같은 3 가지의 특징들을 보인다. 첫째, 공통적으로 인적 준거들을 강조하고 있다. 학습자와 교 원(교장 및 교사)을 중심으로 살펴 본 초기의 연구에서 점차적으로 학부모, 전문가 집단, 지역사회 인사 등으로 확대·제시하고 있다. 둘째, 교육내용, 계열화, 수업, 프로 그램 등으로 내용과 관련된 준거들을 제시하고 있다. 셋 째, 교육기관을 둘러싼 물질적·조건적 상황, 분위기 등의 환경적 준거들을 제시하고 있다.

다음의 Table 2 는 국내외의 학자들이 제시한 $\mathrm{SBCD}$ 의 준거들을 나열하고, 앞선 공통된 특징을 일정 영역으로 간주하여 분류한 것이다. 
[Table 2] SBCD factor categorization according to scholars showed

\begin{tabular}{|c|c|c|c|c|}
\hline \multirow{2}{*}{$\begin{array}{l}\text { scholar } \\
\text { name } \\
\text { (year) }\end{array}$} & \multirow[b]{2}{*}{ SBCD Factors } & \multicolumn{3}{|c|}{ Field } \\
\hline & & Human & content & $\begin{array}{l}\text { environ } \\
\text { ment }\end{array}$ \\
\hline $\begin{array}{c}\text { Saylor \& } \\
\text { Alexander } \\
(1974)\end{array}$ & $\begin{array}{l}\text { Data of learner, Data of society, } \\
\text { Data of Knowledge }\end{array}$ & 0 & 0 & 0 \\
\hline $\begin{array}{c}\text { MacDona } \\
-1 \mathrm{~d} \\
(1986)\end{array}$ & $\begin{array}{l}\text { curriculum expert, teacher, } \\
\text { student, principal, super } \\
\text { advisor, citizen, } \\
\text { parents, publisher }\end{array}$ & 0 & $\times$ & $x$ \\
\hline $\begin{array}{l}\text { Print } \\
(1993)\end{array}$ & $\begin{array}{l}\text { learner \& learning } \\
\text { theory(psychology), } \\
\text { life(culture \& sociology), } \\
\text { properties \& value of knowledge }\end{array}$ & O & $\mathrm{O}$ & 0 \\
\hline $\begin{array}{c}\text { Posner } \\
\text { (1995) }\end{array}$ & $\begin{array}{l}\text { time based } \cdot \text {, physic based, } \\
\text { politic-legal based, systematic, } \\
\text { human, economic, } \\
\text { cultural factors }\end{array}$ & $\mathrm{O}$ & $x$ & 0 \\
\hline $\begin{array}{c}\text { Posner } \\
\text { (2004) }\end{array}$ & $\begin{array}{l}\text { goal, philosophical basis } \\
\text { of curriculum \& } \\
\text { educational philosophy, contents, } \\
\text { character of learner, activity, } \\
\text { data, group rule, schedule, } \\
\text { teacher traning \& attitude, } \\
\text { evaluation, management } \\
\text { structure, group member } \\
\& \text { financial restriction }\end{array}$ & 0 & 0 & 0 \\
\hline $\begin{array}{c}\text { Hebowitsh } \\
\text { (2005) }\end{array}$ & $\begin{array}{l}\text { character of learner, } \\
\text { value \& goal of society }\end{array}$ & 0 & 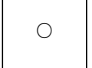 & 0 \\
\hline $\begin{array}{l}\text { Chen Li } \\
(2006)\end{array}$ & $\begin{array}{l}\text { material factors(knowledge, } \\
\text { technology, experience, } \\
\text { activity, pattern \& method, } \\
\text { emotional attitude, } \\
\text { values \& establishment goal), } \\
\text { conditioning factors(human, } \\
\text { time, space, medium, } \\
\text { environmental knowledge } \\
\text { situation of curriculum) }\end{array}$ & 0 & $\bigcirc$ & 0 \\
\hline $\begin{array}{l}\text { Wiles \& } \\
\text { Bondi } \\
(2007)\end{array}$ & $\begin{array}{l}\text { society, knowledge, } \\
\text { peculiarities of learner } \\
\text { development, } \\
\text { learning \& engineering }\end{array}$ & O & 0 & 0 \\
\hline $\begin{array}{c}\text { Doo-Jung } \\
\text {. Kim } \\
(2005)\end{array}$ & $\begin{array}{l}\text { learner factor(cognitive levels } \\
\& \text { form, concep, multiple } \\
\text { inteligence, creativity, interest, } \\
\text { self esteem, morality, } \\
\text { development stage) }\end{array}$ & 0 & $x$ & $x$ \\
\hline $\begin{array}{l}\text { Young- } \\
\text { Gun. Jung } \\
(2002)\end{array}$ & $\begin{array}{l}\text { principal, teacher, student, } \\
\text { parents, expert group }\end{array}$ & 0 & $x$ & $x$ \\
\hline $\begin{array}{l}\text { Hwa-Suk. } \\
\text { Choi } \\
(2011)\end{array}$ & $\begin{array}{l}\text { principal, teacher, student, } \\
\text { parents, local community person }\end{array}$ & O & $x$ & $x$ \\
\hline
\end{tabular}

Table 2에서와 같이 비록 용어상의 차이는 있지만 대 부분의 학자들이 제시하는 인적영역, 내용영역, 환경영역 은 $\mathrm{SBCD}$ 상에 고려해야 할 요인들을 분류하는 틀로 제 시될 수 있다.

\section{4. 우리나라 $\mathrm{SBCD}$ 의 문제점}

공모의 방식( $1 \cdot 2$ 차 서류전형)으로 선정된 $\bigcirc \bigcirc$ 도 교육 과정 연구위원들(초·중등 교장2명, 교사8명으로 구성)과 함께 ' $\mathrm{SBCD}$ 의 문제점과 향후과제'라는 주제로 총 2회 (2012. 12. 19, 2013. 01. 09)에 걸쳐 전문가협의회(Focus Group Interview)를 개최하였다. 자료의 분석은 협의내 용을 충실히 전사하고 의사소통에 문제가 생긴 내용들에 대해 재차 유선전화 등으로 되묻는 과정을 통해 모호함 을 보완한 후, 유사내용을 중심으로 유목화를 통해 분석 하였다.

협의내용은 지금까지 단위학교에서 수행해왔던 $\mathrm{SBCD}$ 의 문제점들을 중심으로 $\mathrm{SBCD}$ 의 과정에 비중있게 고려 되어야 할 활동들이 무엇인지에 관한 논의들이 이루어졌 다.

\section{<제 1 차 협의회>}

제 1 차 협의회에서 주로 논의된 사항은 고시와 지침의 지배 속에 현실적으로 $\mathrm{SBCD}$ 의 자율성을 발휘할 부분이 얼 마 없고, 연구학교의 자료는 대부분 우수사항만을 나열하 여 긍정적인 부분만을 부각하고 있으며, 방과후 교육과정 은 나름대로 창안의 형태를 나타낼 수 있으며, 동일한 사안 에 대해 학교장과 교사의 입장에서 각각 학교운영차원과 업무과중 차원으로 상이한 인식이 발생하고, 단위학교마다 처해진 어려움이 지역·규모별로 다르다는 의견들이 있었 다.

- 관련예시 발췌

$\bigcirc$ 한 00 교장

- 교육과정 지침이 너무 구체화되어 있는 현실에서 자 율성을 발휘할 부분이 얼마 없다고 생각함. 교육부 에서는 이래저래 자율성을 확보하라고 하지만 지역 교육지원청까지 내려오면 중요시하는 중점 사항들 이 너무 많아짐.

- '교과’면 교과, ‘방과 후’면 방과후, ‘창체’면 창체, 각 영역별로 분리된 자료를 개발하는 것이 실효성이 있을 것으로 판단됨. (중략)

$\bigcirc$ 김00교사

- 방과후 교육과정은 그런대로 창안하여 구성할 수 있 다고 생각함. 참여정부 시절부터 지속적으로 강조해 왔고, 주변 학교담당자들과 사석에서 애기 해봐도 저마다 특색있는 프로그램들을 몇 가지씩 운영하고 
있었음(사례에 대해 이야기 함).

- 정규교육과정은 교사수급과 관련해 저마다의 이해 관계가 얽혀 있어 손대기 어려운 부분들이 있음. (중략)

\section{<제 2 차 협의회>}

제2차 협의회에서 주로 논의된 사항은 $\mathrm{SBCD}$ 의 다양한 개발-운영 사례가 필요하고, 구성원의 노력과 의지가 핵심 요인이라 생각되고, 교육과정의 '질 관리'와 지역차 극복이 필요하고, 학교교육과정위원회의 기능회복이 필요하고, 학교에 대한 신뢰회복과 교육공동체 구축이 선행되어야 하 고, 교사의 전문성 신장을 위해 노력해야 하고, 전문성의 범위가 확장되어 이해될 필요가 있으며, 학생의 안전과 학 교폭력 추방을 위해 인성지도가 강화되어야 하고, 우수한 $\mathrm{SBCD}$ 라는 것은 다양한 요인들을 고려해야 한다는 의견들 이 비중있게 다루어졌다.

- 관련예시 발췌

$\bigcirc$ 박 00 교장

- 소규모 학교는 편성 및 운영 자체가 힘이 듬. 다양 한 $\mathrm{SBCD}$ 개발-운영사례가 예시적으로 필요함. 또 한 도교육청이나 지역교육지원청은 지원에만 치중 했으면 좋겠고, 단위학교 편성·운영에 대한 지나친 감독을 지양했으면 함(본인의 학교가 농촌 소규모 학교이며, 그에 따른 어려움이 많다는 부분을 토 로). (중략)

$\mathrm{O}$ 최00교사

- $\mathrm{SBCD}$ 는 업무담당자만이 하는 일로 알고 있음. 학 교교육과정위원회가 있지만 조직만 해놨지, 현재 저와 교감선생님 정도만 관심이 있음. 자신이 어느 분과에 있는 지 관심조차 없는 사람이 상당수 있 고, 사실 스스로의 업무에 바빠서 무엇을 요청하기 도 미안함. 개인적으로는 학교교육시스템을 개선 해서 교원의 다양한 연구시간을 확보한 사례가 우 수 $\mathrm{SBCD}$ 사례라고 판단됨. 하루 8시간에서 4시간 수업, 급식지도, 잡무처리 등을 하고나면 여유시간 이 없음(업무경감의 필요성을 토로). (중략)

2차례에 걸친 전문가 협의회를 통해 얻을 수 있는 시 사점으로는 첫째, $\mathrm{SBCD}$ 를 둘러싼 여러 가지 개념변화와 확대되어가는 자율성에 대해 아직까지 올바른 인식이 부 족했다는 것이다. 학교단위로 현직연수를 월 1 2회 가
량 실시하고 있으나, $\mathrm{SBCD}$ 의 큰 틀이나 세계적인 추세 및 동향, 개념 확장 등에 대해서 연수된 바는 없고, 대부 분이 바뀌는 제도와 학교입장에서 이루어지는 행정처리 부분에 초점을 맞추고 있어, 향후 개선이 필요함을 알 수 있었다.

둘째, $\mathrm{SBCD}$ 관련 참고자료의 개발·보급이 필요했다. 기존의 형식적인 문서(보고서, 장학자료)에서 탈피하여, 다양한 방법을 활용한 실제적인 자료개발이 필요한데, 최근 전국의 $\mathrm{SBCD}$ 우수교를 전 교직원이 방문해 분야별 로 벤치마킹을 하려는 시도들은 좋은 예라 할 수 있다.

셋째, 효과적인 $\mathrm{SBCD}$ 를 위한 요인들에 대해 현장전 문가들도 저마다 다양한 생각과 상이한 가치부여를 하고 있었다. 대체적으로 인적자원의 노력과 충실한 내용구성, 다양한 지원과 협조체계가 중요하다고 공감했지만, 지역 과 규모, 학교 대·내외적 여건 등이 다양함에 따라 똑같 은 사안을 바라보는 이해당사자들 간의 시각도 상이했다.

\section{5. $\mathrm{SBCD}$ 의 요인}

$\mathrm{SBCD}$ 의 개념변화와 다양한 연구흐름들을 바탕으로 구성요소와 원리 및 준거 탐색을 종합적으로 고려하여, 본 연구에서는 $\mathrm{SBCD}$ 에 고려해야 할 요인들을 크게 인 적·내용·환경의 3 가지 영역으로 나누었다. 각 영역에 해 당하는 구체적인 내용들은 다음과 같다.

\section{1 인적영역}

문헌분석의 결과 $\mathrm{SBCD}$ 에 영향을 미치는 인적영역의 요인들로는 학교장, 교사, 학생, 학부모, 지역사회인사, 각 종 교원단체, 전문가집단 등이 폭넓게 포함될 수 있었다. 하지만 이러한 인적요인들 가운데 현장학교와의 접근성 과 참여성을 감안할 때, 각종 교원단체와 전문가집단은 $\mathrm{SBCD}$ 의 인적요인과는 거리가 있었다. 다음으로 $\mathrm{SBCD}$ 에 직접적으로 참여하며 많은 역할을 수행하는 학교장과 교사는 중요도를 감안할 때, 직접참여요인으로 볼 수 있 고, 수요조사나 만족도조사 및 각종 위원회를 통해 의견 을 간접적인 방식으로 반영하는 학생, 학부모를 간접참 여요인으로 구분할 수 있다. 마지막으로 지역사회인사는 학교교육과정 개발에 미치는 영향력은 미약하나 학교운 영위원회의 지역위원으로 학교환경 개선 및 교과용 도서 의 선정 등에 부분적으로 참여하기 때문에 기타참여요인 
으로 간주된다.

\section{2 내용영역}

$\mathrm{SBCD}$ 의 개념확대 부분에서 논의한 바와 같이 내용영 역을 구성하는 요인들은 $\mathrm{SBCD}$ 의 자율성 발휘정도에 따 라 하나의 단위학교 교육과정 내에서도 채택·재구성·창 안의 형태가 모두 나타날 수 있다. 전문가협의회에서의 논의와도 같이 최근 방과후 교육과정이나 학교별 특색프 로그램 등은 자체적으로 개발·운영하는 경우가 많고, 그 비중도 확대되고 있어 상대적으로 자율성을 발휘하기 힘 든 교과와 창의적 체험활동 중심의 정규교육과정과는 구 별될 필요가 있다.

본 연구에서의 내용요인이란 학교에서 제공하는 모든 교육프로그램을 의미한다. 즉 학교교육과정 문서가 실제 적으로 구현되는 형태는 정규교육과정상의 교과와 창의 적 체험활동이지만, 방과후 교육과정이나 특색프로그램 역시 학교에서 제공하는 교육프로그램의 일종이므로 내 용요인은 이들 모두를 포함해야 한다는 것이다. 따라서 학교교육과정을 크게 정규교육과정, 방과후학교 교육과 정, 기타 특별 프로그램으로 나누고, 각각은 $\mathrm{SBCD}$ 의 내 용영역을 구성하는 요인으로 간주될 수 있다.

\section{3 환경영역}

$\mathrm{SBCD}$ 의 환경영역과 관련해 Skilbeck(1984)은 지금까 지 중요성의 인식에 비해 구체적인 내용제시가 미약했다 고 지적하고, 학교의 환경을 구성원(학생과 교사)의 정의 적 요소(가치·태도·역할)와 관련된 내적 환경요인과 학교 풍토·권위관계·정치구조 등의 외적 환경요인으로 구분하 였다[5]. 이러한 구분은 학교환경에 대한 의사결정권의 위치를 중시하고 있다. 앞선 $\mathrm{SBCD}$ 의 준거탐색에서 환경 영역과 관련된 부분들을 이러한 관점에서 본다면 조직구 조, $\mathrm{SBCD}$ 시기 및 계획, 학교시설과 분위기, 설립형태, 예 산, 협의기구들, 학부모의 요구 등은 학교에서 자체적으 로 의사결정권을 행사하므로 내적 환경요인으로 볼 수 있고, 문화적-사회적 변화와 지역사회의 가치, 가르쳐야 할 교과의 성격변화, 학교를 위한 외부 자원 등은 상대적 으로 외적 환경요인이라 할 수 있다.

문헌분석의 결과를 중심으로, 본 연구는 단위학교의 $\mathrm{SBCD}$ 와 관련된 다양한 환경요인 중 내적 환경요인에 주 목하고, 전문가협의회에서 효과적인 $\mathrm{SBCD}$ 를 위한 학교 환경의 개선점으로 제기된 문제점들을 고려하여, 교수-
학습 지원체계 구축, 물리적 교육여건 개선, 학교구성원 의 내부역량 강화를 위한 노력을 중요한 환경요인으로 간주하였다.

이상의 내용들을 정리하여, 본 연구에서 도출한 $\mathrm{SBCD}$ 요인은 3 가지 영역의 9 가지 요인으로 다음의 Table 3과 같다.

[Table 3] School curriculum development factors

\begin{tabular}{|c|c|c|}
\hline field & $\begin{array}{l}\text { organization } \\
\text { factor }\end{array}$ & detail factor \\
\hline \multirow{3}{*}{ human } & $\begin{array}{l}\text { direct } \\
\text { paticipant } \\
\text { factors }\end{array}$ & principal, teachers \\
\hline & $\begin{array}{l}\text { indirect } \\
\text { paticipant } \\
\text { factors }\end{array}$ & students, parents \\
\hline & $\begin{array}{l}\text { other } \\
\text { paticipant } \\
\text { factors }\end{array}$ & $\begin{array}{l}\text { region human } \\
\text { resources }\end{array}$ \\
\hline \multirow{3}{*}{$\begin{array}{l}\text { conte- } \\
\text { nts } \\
\text { field }\end{array}$} & $\begin{array}{l}\text { regular } \\
\text { school } \\
\text { curriculum }\end{array}$ & $\begin{array}{l}\text { a course of subject, } \\
\text { creative experiential } \\
\text { activities }\end{array}$ \\
\hline & $\begin{array}{l}\text { after } \\
\text { school } \\
\text { curriculum }\end{array}$ & $\begin{array}{l}\text { after school curriculum } \\
\text { (except regular school } \\
\text { curriculum) }\end{array}$ \\
\hline & $\begin{array}{l}\text { other } \\
\text { special } \\
\text { program }\end{array}$ & $\begin{array}{l}\text { self school development } \\
\text { program }\end{array}$ \\
\hline \multirow{3}{*}{$\begin{array}{l}\text { enviro- } \\
\text { nment }\end{array}$} & $\begin{array}{l}\text { support } \\
\text { system }\end{array}$ & $\begin{array}{l}\text { instruction \& learning } \\
\text { support system for } \\
\text { student \& parents }\end{array}$ \\
\hline & $\begin{array}{l}\text { education } \\
\text { eavironment }\end{array}$ & $\begin{array}{l}\text { physical education } \\
\text { enviroment }\end{array}$ \\
\hline & $\begin{array}{l}\text { school } \\
\text { mood }\end{array}$ & $\begin{array}{l}\text { a effort for inner } \\
\text { competence } \\
\text { reinforcement } \\
\text { of school community } \\
\text { members }\end{array}$ \\
\hline
\end{tabular}

\section{6. 결론 및 논의}

본 연구는 $\mathrm{SBCD}$ 의 개념과 범위에 대해 공통된 합의 가 모호한 현 시점에서, $\mathrm{SBCD}$ 의 개념변화를 파악하고 비중있게 고려해야 할 요인이 무엇인가에 주목하여, 효 과적인 $\mathrm{SBCD}$ 와 지속적인 갱신을 위한 이해의 토대를 마 련하고자 하였다. 구체적인 연구방법으로 먼저 충분한 문헌분석을 실시하였다. 구체적으로 $\mathrm{SBCD}$ 와 관련된 학 위논문, 학술지, 단행본, 연구보고서 및 학교교육과정 문 서를 대상으로 $\mathrm{SBCD}$ 의 구성요소와 원리, 준거 및 요인 등에 관해 검토·분석하였고, $\mathrm{SBCD}$ 를 검색어로 국회전자 도서관에 등록된 1995 년 이후 총 56 편의 논문에 대해 메 
타분석을 실시하여 연구패턴에 따른 시사점을 추출하였 다. 또한, 2 차에 걸친 전문가협의회를 통해 현행 $\mathrm{SBCD}$ 의 문제점을 진단하였다. 이러한 과정을 통해 도출된 결과 들은 다음과 같다.

첫째, $\mathrm{SBCD}$ 의 개념이 단위학교가 자율성을 바탕으로 다양한 현실을 고려하여 교육과정을 '창안'하는 활동으로 확대되어 인식될 필요가 있다. 현재 우리나라의 $\mathrm{SBCD}$ 는 국가수준 교육과정에 대한 수용정도에 따라 채택, 재구 성, 창안으로 나눌 수 있었다. 하지만 이러한 구분은 주로 교과와 창의적 체험활동으로 구성되는 정규교육과정에 적용될 수 있고, 방과후 교육과정이나 학교 특색 프로그 램과 같은 경우에는 보다 새로운 관점에서 이해되어야 할 필요가 있었다. 또한, 대부분의 연구들은 현재 다양해 진 인적요인들을 부분적으로만 포함하고 있었으며, 학교 의 환경요인에 대해서도 지역의 실태나 물리적 환경 정 도만을 제한적으로 언급하고 있었다. 이는 $\mathrm{SBCD}$ 에 대한 역사적 고찰을 시도한 연구들에서도 그간의 $\mathrm{SBCD}$ 연구 가 다양한 요인들을 포괄적으로 제시하는데 미흡했었다 는 지적들과도 맥락을 함께 한다[31]. 지금까지의 제한된 개념정의에서 벗어나는 것은 현재 $\mathrm{SBCD}$ 와 관련해 폭넓 게 영향력을 발휘하고 있는 다양한 자원들의 역동성을 수용함에도 타당한 근거가 될 수 있다.

둘째, 전문가협의회의 분석 결과, $\mathrm{SBCD}$ 에 대한 국가 와 단위학교의 이해가 상이했다. 국가에서는 지속적인 $\mathrm{SBCD}$ 의 자율화 정책을 추진하고 있지만, 단위학교에서 는 이에 대한 올바른 인식이 부족했고, 때때로 자율화가 불필요하다고 느끼는 경향이 있었다. 또한 단위학교의 $\mathrm{SBCD}$ 를 돕기 위한 자료가 부족하고, 기존의 형태(보고 서, 장학자료)에서 탈히한 실제적인 자료개발이 필요하 다는 의견이 지배적이었다. 이는 교원의 $\mathrm{SBCD}$ 능력신장 에 자료의 미흡이 저해요소로 작용할 수 있다는 선행연 구와도 맥락을 함께 한다[4].

셋째, 문헌분석과 전문가협의회를 통해, $\mathrm{SBCD}$ 에 비중 있게 고려해야 할 요인을 3 가지 영역(인적·내용·환경)의 9 가지 요인(학교장, 교사, 학생, 학부모, 지역사회인사, 정 규교육과정, 방과후교육과정, 기타특별 프로그램, 학교의 교육환경)으로 분류하였다.

결론적으로 바람직한 $\mathrm{SBCD}$ 를 위해서는 인적영역을 구성하는 요인들이 $\mathrm{SBCD}$ 의 개념변화와 중요성을 인식 하고 개발과 개선의 과정에 적극적으로 기여해야 하고, 이러한 기여들은 정규교육과정, 방과후 교육과정, 학교
특색프로그램을 충실히 계획·전개하는 것을 통해 드러나 게 되며, 학교의 물리적 환경개선과 다양한 교육지원체 제 구축 등은 $\mathrm{SBCD}$ 의 전반에 걸쳐 적합한 토대형성 차 원에서 필요함을 알 수 있었다.

향후, 효과적인 $\mathrm{SBCD}$ 를 위해 학교현장의 복잡성과 점점 확장되는 개념변화를 반영하여 보다 폭넓은 요인들 에 지속적인 관심을 기울여야 할 것이다. 구체적으로 본 연구에서 제시한 3 가지 영역의 중요도나 각 요인별 영향 력의 행사정도를 파악해보는 연구가 필요하고, 영역별, 세부요인별, 하위요소별 중요도를 측정하여, 핵심요인을 재구조화하려는 후속 연구가 있어야 할 것이다.

\section{References}

[1] Beattie. M, Thiessen. D, "School-based reconstructing and curriculum change", Curriculum Journal, 8, pp. 411-440, 1997.

DOI: http://dx.doi.org/10.1080/0958517970080306

[2] Brady. L, "Curriculum development", New York: Prentice Hall, 1987.

[3] S. Y. Hong, Y. M. Kim, "A Study on Primary School Teacher's Attitute \& Perception about SBCD", Korea Educational Problem Researc, 12, pp. 1-21, 1997.

[4] H. S. Choi, " A Teacher Ability Model Development to SBCD", Korea National university Education Graduate School of Management Doctorate Thesis, 2011.

[5] Skilbeck. M, "School-based curriculum development", London: Harper \& Row, 1984.

[6] Bezzina. M, "Teachers' perceptions of their participation in SBCD", Curriculum Perspectives, 11(2), pp. 39-47, 1991.

[7] Sabar. N, "School-based curriculum development" Oxford: Pergamon Press, 1991.

[8] B. S. Gwak, "Curriculum explanation", Seoul: Kyoyookgwahaksa, 1987.

[9] J. C. Kim, "Curriculum And Evaluation", Seoul: Kyoyookgwahaksa, 2000.

[10] N. W. Kweon, "SBCD theory", Seoul: Hakgisa, 2008.

[11] The Joint Committee on Standards for Educational Evaluation, "The program evaluation standards(3rd ed.).", Thousand Oaks, CA: Sage publications, 2011.

[12] D. J. Kim, "SBCD Conceps \& Management Factors" Journal of Research Education, 26(2), pp. 171 200, 2005.

[13] C. G. Son, "A Study on SBCD Model", Educational 
Research, 19, pp. 195-217. 2000.

[14] Chen. L, "Analysis on the effective development system of curriculum resources", US-China Education Review, 3(5), pp. 1-10, 2006.

[15] Fuquan. H, "Curriculum reform in contemporary China: Seven goals and six strategies", Journal of Curriculum Studies, 36(1), pp. 101-115, 2004.

DOI: http://dx.doi.org/10.1080/002202703200004742000174126

[16] Gopinathan. S, Deng. Z, "Fostering school-based curriculum development in the context of new educational initiatives", The Journal of Planning \& Changing, 37, pp. 93-110. 2006.

[17] OECD, "School-based curriculum development", Paris: CEM/OECD, 2006.

[18] Lauridsen. D. A, "What are teachers' perception of the curriculum development process?", Doctorial dissertation, Ohio State University, 2003.

[19] G. H. Hwang, "Curriculum's Development \& Management", Curriculum Research, 13, pp. 25-38, 1995.

[20] Kesson. K, Oyler. C, "Integrated curriculum and service learning: Linking school-based knowledge and social action", English Education, 31, pp. 135-149, 1999.

[21] Lo. Y, "SBCD: The Hong Kong experience", The Curriculum Journal, 10(3), pp. 419-442, 1999.

DOI: http://dx.doi.org/10.1080/0958517990100307

[22] Hui. L, "SBCD: An interview study of chinese kindergartens" Early Childhood Education Journal, 33, 223-229. 2006.

DOI: http://dx.doi.org/10.1007/s10643-006-0061-7

[23] Shkedi. A, "SBCD workshops for teacher participation in curriculum development" Journal of curriculum studies, 28(6), pp. 699-712, 1996.

DOI: http://dx.doi.org/10.1080/0022027980280605

[24] Rungnapa. N, "SBCD decision-making: A study of the Thailand reform experiment", Doctorial Dissertation, Indiana University, 2002.

[25] Law. E. H, Galton. M, Sally. Wai-Yan. Wan, "Developing curriculum leadership in schools: Hong Kong perspectives", Asia-Pacific Journal of Teacher Education, 35, pp. 143-159, 2007. DOI: http://dx.doi.org/10.1080/13598660701268569

[26] Glatthorn. A. A, "Developing a quality curriculum", Alexandria, Virginia: ASCD, 1994.

[27] Marsh. C, \& Willis. G, "Curriculum alternatives, ongoing issues(2nd ed.)”, NJ: Prentice Hall, 1999.

[28] Doll. R. C, "Curriculum improvement", Boston: Allyn
\& Bacon, 2008.

[29] Tyler. R. W, "Basic principles of curriculum and instruction", Chicago, IL: The U niversity Chicago Press, 1949.

[30] Schwab. J. J, "The Practical: A language for curriculum", School review, 78, pp. 1-23, 1969.

DOI: http://dx.doi.org/10.1086/442881

[31] Hogan, R, L. (2007). The historical development of program evaluation: Exploring the past and present. Online Journal of Workforce Education and Development, 2(4), 1-14.

\section{이 재 철(Jae-cheol Lee)}

[정회원]

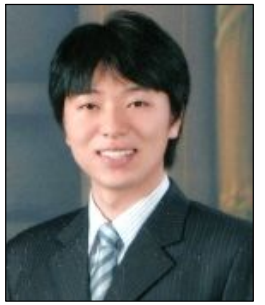

- 1998년 2월 : 한국교원대학교 졸 업(교육학사)

- 2006년 2월 : 고려대학교 교육학 과 졸업(교육학석사)

- 2012년 8월 : 한국교원대학교 교 육학과 교육과정 전공(교육학박사)

- 2010년 9월 현재 : 한국교원대 교육학 강사

- 2000년 9월 현재 : 중등학교 교사로 재직 중

<관심분야>

학교교육과정, 학습모형, 효과적인 수업설계

최 화 숙(Hwa-Sook Choi)

[정회원]

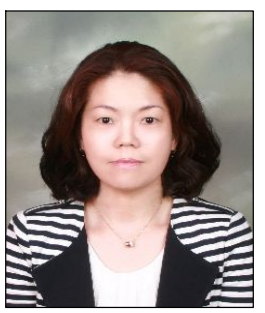

- 1996년 2월 : 한국교원대학교 졸 업(교육학사)

- 2008년 2월 : 한국교원대학교 교 육학과(교육학석사)

- 2011년 2월 : 한국교원대학교 교 육학과 교육과정 전공(교육학박사)

- 2011년 3월 현재 : 서남대학교 재직 중

<관심분야>

교사교육, 학교교육과정 개발, 프로그램 개발 